\title{
LETTER
}

\section{Dispersal-mediated trophic interactions can generate apparent patterns of dispersal limitation in aquatic metacommunities}

Dino Verreydt, ${ }^{1 *}$ Luc De Meester, ${ }^{1}$ Ellen Decaestecker, ${ }^{2}$ María-José Villena, ${ }^{3 \dagger}$ Katleen Van Der Gucht, ${ }^{3}$ Pieter Vannormelingen, ${ }^{3}$ Wim Vyverman ${ }^{3}$ and Steven A.J. Declerck $^{4}$

\begin{abstract}
Dispersal is a major organising force in metacommunities, which may facilitate compositional responses of local communities to environmental change and affect ecosystem function. Organism groups differ widely in their dispersal abilities and their communities are therefore expected to have different adaptive abilities. In mesocosms, we studied the simultaneous compositional response of three plankton communities (zoo-, phytoand bacterioplankton) to a primary productivity gradient and evaluated how this response was mediated by dispersal intensity. Dispersal enhanced responses in all three planktonic groups, which also affected ecosystem functioning. Yet, variation partitioning analyses indicated that responses in phytoplankton and bacterial communities were not only controlled by dispersal directly but also indirectly through complex trophic interactions. Our results indicate that metacommunity patterns emerging from dispersal can cascade through the food web and generate patterns of apparent dispersal limitation in organisms at other trophic levels.
\end{abstract}

\section{Keywords}

Bacterioplankton, dispersal, ecosystem function, indirect effects, metacommunity, phytoplankton, productivity, species sorting, trophic cascade, zooplankton.

Ecology Letters (2012)

\section{INTRODUCTION}

Dispersal is a major structuring force in metacommunities, also affecting the composition, diversity and functioning of local communities (Loreau et al. 2003; Matthiessen \& Hillebrand 2006; Duffy 2009; Hillebrand \& Matthiessen 2009; Howeth \& Leibold 2010). The qualitative and quantitative effects of dispersal are, however, difficult to predict and depend on many factors, such as the intensity of dispersal, the functional traits of the organisms, and the occurrence of complex ecological interactions. Dispersal can lead to increased local species richness because it allows new species to enter communities and compensate for local extinctions (Loreau \& Mouquet 1999). Dispersal can also facilitate a rapid and efficient compositional response of local communities to changing environmental conditions through the process of species sorting. At the metacommunity level, this process can lead to enhanced differentiation among communities and an increase in beta diversity (Cottenie \& De Meester 2004; Leibold \& Norberg 2004). Conversely, dispersal can also increase the probability of invasions by superior competitors, predators or parasites potentially causing extinctions of local populations or entire metapopulations. In the case of mass effects, high dispersal rates may result in the presence of species in unsuitable habitat patches, and lead to a homogenisation of metacommunities (Mouquet \& Loreau 2003).

Lack of dispersal, on the other hand, may impede species to reach potentially suitable habitat patches (Loreau et al. 2003; Ozinga et al.
2005; McCauley 2006; Pärtel \& Zobel 2007). At the local scale, this reduces the capacity of resident communities to track environmental change, which may have a profound impact on the performance of entire functional groups or trophic levels and as such affect ecosystem functioning. Although empirical evidence remains scarce, there are a limited number of recent experimental studies that have demonstrated such effects. Naeslund \& Norberg (2006) found stronger responses of zooplankton communities to a change in basal productivity if the communities at the start of the experiment represented the entire regional species pool instead of just local pools. They also found that the communities resulting from the regional species pool treatment exerted stronger top-down control on phytoplankton than the communities resulting from local species pools. Howeth \& Leibold $(2008,2010)$ showed that dispersal can affect ecosystem stability and dampen trophic cascade effects in plankton communities that are subject to temporal fluctuations in the density of a top predator.

Metacommunity structure varies widely among organism groups (Beisner et al. 2006). One potential reason for this is that dispersal capabilities of organisms vary greatly (Bohonak \& Jenkins 2003; Jenkins et al. 2007). Microbial organisms, for example, are supposed to have very high dispersal rates (Finlay \& Clarke 1999; Finlay 2002), in contrast to passively dispersing macroscopic organisms of which dispersal rates tend to decrease with increasing body size (Jenkins $e t$ al. 2007; Shurin et al. 2009). An additional level of complexity may be generated by indirect mechanisms, such as dispersal-mediated trophic interactions. Indeed, the metacommunity structure of a group of

\footnotetext{
${ }^{1}$ Laboratory of Aquatic Ecology and Evolutionary Biology, K. U. Leuven, Charles Deberiotstraat 32, B-3000 Leuven, Belgium

${ }^{2}$ Aquatic Biology, K. U. Leuven- Campus Kortrijk, E. Sabbelaan 53, B-8500 Kortrijk, Belgium

${ }^{3}$ Protistology \& Aquatic Ecology, Ghent University, Krijgslaan 281-58, B-9000

Ghent, Belgium
}

\author{
${ }^{4}$ Netherlands Institute of Ecology (NIOO-KNAW), P.O. Box 50, $6700 \mathrm{AB}$ \\ Wageningen, The Netherlands \\ *Correspondence: E-mail: dino.verreydt@bio.kuleuven.be \\ ${ }^{\dagger}$ Present address: Laboratorios Tecnológicos de Levante SL. C/Leonardo da Vinci \\ 4, Parque Tecnológico, 46980 Paterna, Valencia, Spain
}


organisms that is strongly affected by trophic interactions can also reflect patterns resulting from spatial dynamics at other trophic levels. In such case, an association between connectivity patterns and the metacommunity structure of an organism group does not unequivocally reflect dispersal limitation or mass effects (Staddon et al. 2010).

With this study, we wanted to explore the direct and indirect effects of dispersal on the composition and functioning of communities representing different trophic levels within a metacommunity context. We used freshwater plankton in mesocosms as a model system and performed an experiment combining varying degrees of dispersal with an important environmental gradient (i.e. a gradient in primary productivity) according to an orthogonal design. The main objectives of our study were to (1) study the extent to which dispersal can mediate the response of plankton organisms to a change in basal productivity, (2) compare these responses among three functional groups of plankton organisms that differ widely in body size, life strategy and expected dispersal rates (i.e. zoo-, phyto- and bacterioplankton), (3) evaluate the consequences of dispersal on food web structure and a crucial ecosystem function (i.e. zooplankton grazing on phytoplankton) and (4) evaluate whether the response of the functional groups to the dispersal gradient is caused directly by dispersal itself or rather indirectly by changes in trophic interactions that are caused by dispersal-mediated community shifts at other trophic levels. In the absence of positive size-selective predators, grazing by large-bodied cladoceran zooplankton can strongly affect community composition of phytoplankton and bacterioplankton (Jürgens 1994; Lampert 2006). We therefore expect that dispersalenhanced differentiation of zooplankton communities along a productivity gradient may generate patterns of community differentiation at lower trophic levels that appear to be caused by dispersal limitation, but in fact are generated by indirect dispersal-mediated trophic interactions.

\section{MATERIAL AND METHODS}

\section{Experimental design}

Using mesocosms $(n=96)$, we studied the simultaneous interactive effects of nutrient addition and dispersal on communities of planktonic bacteria, phytoplankton and zooplankton. For this, we first collected plankton from 16 lakes (LAKE ID) representing a broad gradient in trophic state and limnological characteristics. The plankton of each of these lakes was used to inoculate six mesocosms per lake $(6 \times 16=96$ mesocosms $)$ at the start of the experiment (see Appendix S1). In each of these sets of six mesocosms, we created two levels of nutrient addition and three levels of dispersal intensity, so that the entire experimental set-up accorded to a cross-factorial randomised block design (with LAKE ID as blocks). With the dispersal treatment, we tried to achieve a broad range of dispersal intensities among our experimental containers, ranging from no dispersal (NDISP) to strong dispersal. In each block, the NDISP and low dispersal (LDISP) mesocosms were inoculated with plankton originating from one single lake. In contrast, the high dispersal (HDISP) mesocosms were initially inoculated with a plankton mixture from all 16 lakes (see below for details). During the entire experiment, we tried to prevent any input of organisms from other mesocosms into the NDISP-mesocosms. The communities in these mesocosms thus consisted solely of species collected from one individual lake, although some airborne exchange of phytoplankton and bacteria could probably not be entirely excluded. For the other two dispersal levels, we achieved dispersal by manually exchanging water among mesocosms. For this, we collected water from all mesocosms of the respective dispersal level $(n=32)$ and redistributed the pooled volume in equal parts over the same mesocosms again. In this way, a level of LDISP was achieved through the exchange of $40 \mathrm{~mL}$, whereas the highest dispersal (HDISP) was generated by exchanging $2 \mathrm{~L}$ volumes. We initially applied the dispersal treatment on a weekly basis, but switched to a biweekly treatment from day 59 on until the end of the experiment. The NDISP treatment was meant to represent a metacommunity without dispersal among habitat patches. The LDISP treatment was designed to represent a situation where locally abundant species can disperse in low numbers among habitat patches, with sporadic exchange of locally rare species. The HDISP treatment represents metacommunities with relatively high exchange rates among local communities, where each species has historically had the occasion to enter each habitat patch, but where current dispersal rates are not high enough to cause mass effects (Michels et al. 2001; Howeth \& Leibold 2008).

At day 1 of the experiment (23 May 2006), we filled plastic containers (volume: $200 \mathrm{~L}$ ) with a mixture of $120 \mathrm{~L}$ distilled water and $60 \mathrm{~L}$ tap water. The nutrient treatments were established on days 4 and 5 through addition of phosphate $\left(\mathrm{KH}_{2} \mathrm{PO}_{4}\right)$ and nitrogen $\left(\mathrm{NaNO}_{3}\right)$. Initial nutrient additions were equivalent to $1000 \mu \mathrm{g} \mathrm{P} \mathrm{L}{ }^{-1}$ and $16000 \mu \mathrm{g} \mathrm{N}$ $\mathrm{L}^{-1}$ in the high nutrient (HNUT) containers and $10 \mu \mathrm{g} \mathrm{PL}{ }^{-1}$ and $160 \mu \mathrm{g}$ $\mathrm{N} \mathrm{L}^{-1}$ in the low nutrient (LNUT) containers. As earlier mesocosm experiments have indicated that nutrient gradients can decline with time, we continued with a weekly addition of a tenth of these concentrations throughout the experiment.

We added phytoplankton and bacterioplankton to the containers on the fifth day of the experiment. For this, we collected a $30 \mathrm{~L}$ volume of lake water and filtered it twice (mesh sizes: $100 \mu \mathrm{m}$ and $50 \mu \mathrm{m}$ respectively) to remove zooplankton. NDISP and LDISP mesocosms were all inoculated with an inoculum originating from one individual lake, whereas the inoculum of HDISP mesocosms consisted of a mixture of all 16 lakes (each experimental container received an equal amount of chlorophyll $a$ and for the HDISP mesocosms there was an equal representation of lakes in terms of chlorophyll a). From the moment, we observed a consistent difference in phytoplankton biomass between LNUT and HNUT mesocosms (day 32), we inoculated the zooplankton. Total zooplankton biomass was the same in all inocula. Similar as with the phytoplankton inoculation, we inoculated NDISP and LDISP mesocosms with inocula from individual lakes, whereas HDISP containers received an inoculum for $80 \%$ consisting of the respective lake and for $20 \%$ consisting of a mixture of all 16 lakes. Throughout the experiment, mesocosms were covered by mosquito netting to prevent contamination by macro-invertebrates. The experiment ended at day 87 .

\section{Sampling and sample analysis}

We measured chlorophyll $a$ on a weekly basis with a fluorometer (Trilogy Laboratory Fluorometer, Turner Designs, Sunnyvale, CA, USA). Near the end of the experiment, we sampled the zoo-, phyto-, and bacterioplankton communities. At day 77, we sampled phytoplankton with a $250 \mathrm{~mL}$ jar approximately $10 \mathrm{~cm}$ below the water surface. The phytoplankton samples were preserved with a mixture of Lugol's solution, formaldehyde and sodium thiosulfate (Sherr \& Sherr 1993) and counted using an inverted microscope to the genus level. 
Desmodesmus was a dominant phytoplankton taxon in some treatments of the experiment. Desmodesmus colony size has been shown to be a defence against zooplankton grazing and may therefore serve as an indicator for the prevailing zooplankton grazing regime (Vanormelingen et al. 2009). We therefore characterised the size distribution of Desmodesmus by counting the number of cells per colony in each sample. At day 79, we sampled the bacterioplankton. Samples were filtered over a $0.22-\mu \mathrm{m}$ filter and stored at $-80{ }^{\circ} \mathrm{C}$ for later analysis with denaturing gradient gel electrophoresis (DGGE). DGGE analysis followed Van der Gucht et al. (2007); details are given in Appendix S2. In short, DNA was extracted directly using the beadbeating method concomitant with phenol extraction and ethanol precipitation and purified on a Wizard column. A small rDNA fragment was amplified with primers specific to the domain Bacteria (357F-GC-clamp and 518R). PCR products were analysed on a 35$70 \%$ denaturant DGGE-gel, and DGGE-gels were stained with Sybr Gold solution. The 96 samples were analysed on 12 parallel DGGEgels, which were aligned with Bionumerics 5.10 (Applied Maths BVBA, Kortrijk, Belgium) using three standard lanes (known mixtures of DNA from nine clones from a clone library) on each gel. A matrix was compiled based upon the relative contribution of individual bands to the total band signal in each lane, with bands corresponding to Operational Taxonomic Units (OTUs). Zooplankton samples were taken at day 86 and 87 of the experiment. Two samples were taken in each container with a Schindler Patalas (volume: $12 \mathrm{~L}$; mesh size: $30 \mu \mathrm{m}$ ) and preserved with acid lugol solution. One sample was used to measure zooplankton dry weight. These samples were weighed after drying at $100{ }^{\circ} \mathrm{C}$ during $24 \mathrm{~h}$. The other sample was used for the assessment of species composition and population densities. A minimum of 300 individuals were counted. Taxa were identified to species level for cladocerans using Flössner (2000); for copepods we made a distinction between cyclopoids and calanoids.

\section{Grazing experiment}

Zooplankton grazing is widely acknowledged as a key characteristic of the aquatic food web that determines patterns of energy and material flows and underwater light climate, and may mediate regime shifts in ponds and shallow lakes (Scheffer 1998). To evaluate its importance as potential driving force underlying phyto- and bacterioplankton community responses to the experimental treatments, we performed assays to assess zooplankton grazing pressure on phytoplankton at day 81. In each mesocosm, we incubated two bottles $(250 \mathrm{~mL})$ with mesocosm water, one with ambient zooplankton densities and one without zooplankton (water filtered over $64 \mu \mathrm{m}$ mesh). The bottles were incubated at the bottom of the mesocosms and gently shaken twice a day to keep the phytoplankton in suspension. At day 1 and day 11 of the experiment, we measured the chlorophyll $a$ concentrations with a fluorometer. Per bottle, we calculated the change in chlorophyll $a$, using the formula: $\left(\ln [\mathrm{chl} a]_{\mathrm{t} 11}-\ln [\mathrm{chl} a]_{\mathrm{t} 0}\right) /$ time and used the difference between the treatments as a measure of zooplankton grazing pressure.

\section{Data analysis}

We applied mixed model ANOVA to evaluate the impact of our experimental treatments on chlorophyll a concentration, Desmodesmus colony size, total zooplankton biomass (dry weight) and in situ zooplankton grazing pressure. In these analyses, we specified LAKE ID as a random factor. For chlorophyll $a$, we analysed the time weighted averages so as to give more weight to data that are collected later during the experiment. These averages were calculated for each mesocosm by multiplying each chlorophyll $a$ value with the time that had passed since the start of the experiment (expressed in numbers of days). The sum of these values was then divided by the total duration of the experiment. For Desmodesmus colony size, we analysed the weighted average of cell number. Significant effects were explored with Tukey HSD post hoc tests.

We tested the effects of the experimental treatments on the composition of zooplankton, phytoplankton and bacterioplankton communities with redundancy analysis (RDA). In these analyses, we followed a two-step approach. First, we evaluated the overall effects of the experimental treatments and their potential interactions on each of the communities separately (Lepš \& Šmilauer 2003). Second, we performed variation partitioning analyses (Peres-Neto et al. 2006) on more elaborate RDA models to explore the extent to which indirect trophic interactions can explain apparent dispersal effects in phytoplankton and bacterioplankton. We constructed RDA models for these groups in each of the nutrient addition levels separately with the dispersal treatment and the biomass of the principal zooplankton grazer, Daphnia magna, as explanatory variables. We also included summary variables of phytoplankton community composition as explanatory variables in the RDA model of bacterioplankton because phytoplankton composition can be a determining factor for bacteria and may itself be directly affected by dispersal or indirectly by dispersal-mediated zooplankton grazing. With variation partitioning, we assessed the unique contribution of the dispersal treatment (conditional effect) as well as its degree of collinearity with Daphnia magna density (in the phyto- and bacterioplankton models) and phytoplankton community composition (in the bacterioplankton models). The summary variables for phytoplankton community composition were extracted prior to the RDA analyses through principal components analysis of the phytoplankton data (i.e. the four sample scores vectors with the highest Eigen values; prior analyses

Table 1 ANOVA results testing for the effect of nutrient addition (NUT) and dispersal (DISP) treatments and their interaction on zooplankton dry weight, phytoplankton chlorophyll $a$ and grazing rate of the zooplankton on the phytoplankton. Grazing rates were measured by experiments in situ. LAKE ID refers to the origin of inoculation samples and was specified as a random block factor in the models

\begin{tabular}{lrrccc}
\hline \multicolumn{5}{c}{ d.f. } & \multicolumn{2}{l}{ SS } & MS & \multicolumn{1}{l}{$F$} & $P$-value \\
\hline \multicolumn{2}{l}{ Zooplankton dry weight } & & & & \\
LAKE ID & 15 & 22.30 & 1.49 & 0.91 & 0.585 \\
NUT & 1 & 11.02 & 11.02 & 7.66 & 0.014 \\
DISP & 2 & 18.91 & 9.46 & 5.51 & 0.0092 \\
NUT $\times$ DISP & 2 & 17.88 & 8.94 & 5.9 & 0.0069 \\
Phytoplankton chlorophyll $a$ & & & & \\
LAKE ID & 15 & 0.50 & 0.034 & 1.39 & 0.280 \\
NUT & 1 & 13.52 & 13.52 & 641 & $<0.001$ \\
DISP & 2 & 0.06 & 0.030 & 1.90 & 0.167 \\
NUT $\times$ DISP & 2 & 0.08 & 0.039 & 3.07 & 0.0611 \\
Zooplankton grazing rate & & & & \\
LAKE ID & 15 & 0.035 & 0.0021 & 2.52 & 0.281 \\
NUT & 1 & 0.017 & 0.017 & 14.89 & 0.0016 \\
DISP & 2 & 0.026 & 0.013 & 8.34 & 0.0013 \\
NUT $\times$ DISP & 2 & 0.013 & 0.0065 & 3.44 & 0.0451 \\
\hline
\end{tabular}


(a)

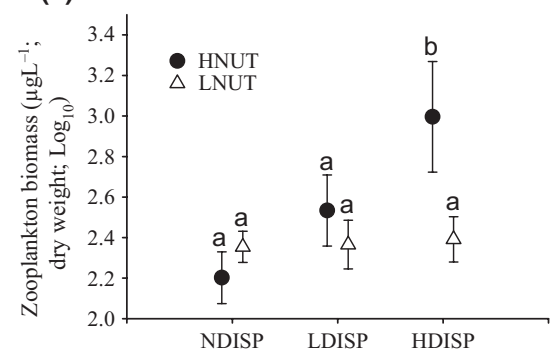

(c)

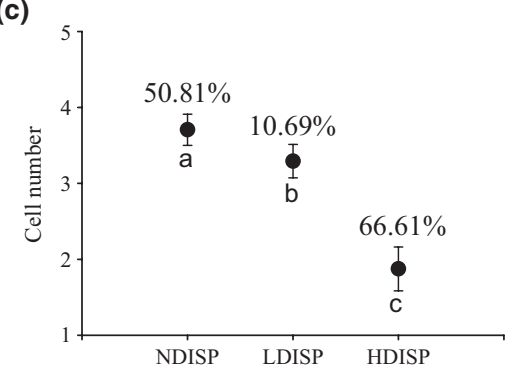

(b)
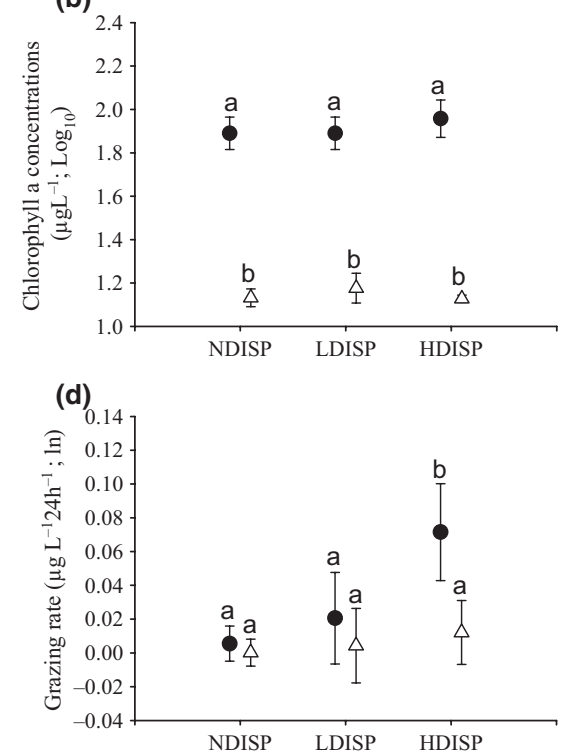

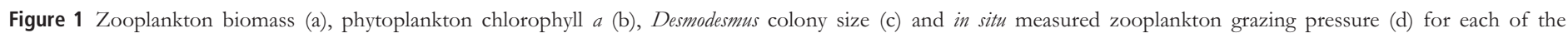

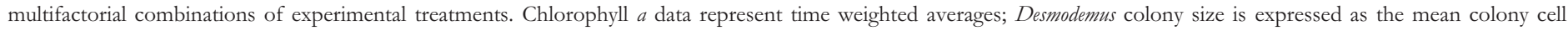

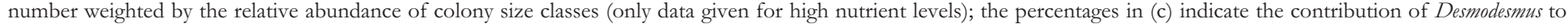

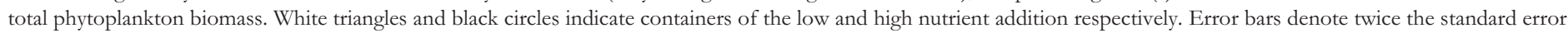
of the mean. Characters indicate significant post hoc differences $(P<0.05)$.

indicated that these four vectors all had a unique and significant contribution to variation in the bacterioplankton community). All community data were Hellinger transformed prior to analysis (Legendre \& Gallagher 2001). Associations of Daphnia magna densities with in situ measured grazing pressure and the weighted average of Desmodesmus colony size were tested with Spearman rank correlation. All statistical analyses were performed in R (v2.10.1; R Development Core Team 2011), using the $\mathrm{rda}$ and varpart functions of the vegan library (Peres-Neto et al. 2006; Oksanen et al. 2010). Adjusted $\mathrm{R}^{2}$ values were calculated on residuals after partialling out the effect of LAKE ID. The significance of model components was tested through 9999 random permutations.

\section{RESULTS}

\section{Zooplankton}

There was a significant nutrient $\times$ dispersal treatment interaction effect on zooplankton biomass (dry weight) (Table 1). Zooplankton biomass was higher in the containers with high than low nutrient addition, but only at high levels of dispersal (Fig. 1A). Similarly, the RDA analyses indicated significant main effects and an interaction effect of the nutrient addition and dispersal treatments on zooplankton community composition (Table 2, Fig. 2A). Separate analyses for each of the dispersal levels showed that the response strength of the zooplankton community to the nutrient addition treatment increased with increasing dispersal, explaining 9, 20 and 59\% of the zooplankton community variation in the no, low and high dispersal treatment respectively (Table 3). Most species responded negatively to high nutrient addition (Fig. 2A). The nutrient by dispersal interaction could almost entirely be attributed to the specific response of the large cladoceran Daphnia magna. The absolute and relative abundance of this species was especially high in high nutrient cattle tanks subjected to
Table 2 Redundancy analysis results, testing for the effect of nutrient addition (NUT) and dispersal (DISP) treatments and their interaction on the variation in the zoo-, phyto- and bacterioplankton community composition in the experimental containers. LAKE ID refers to the origin of inoculation samples and was specified as a random block factor in the models

\begin{tabular}{|c|c|c|c|c|}
\hline Variable & Covariables & $\mathrm{R}^{2}$ & $F$ & $P$-value \\
\hline \multicolumn{5}{|l|}{ Zooplankton } \\
\hline NUT & $\begin{array}{l}\text { DISP } \\
\text { LAKE ID }\end{array}$ & 0.19 & 26.64 & $<0.001$ \\
\hline DISP & $\begin{array}{l}\text { NUT } \\
\text { LAKE ID }\end{array}$ & 0.079 & 5.64 & $<0.001$ \\
\hline NUT $\times$ DISP & $\begin{array}{l}\text { NUT } \\
\text { DISP } \\
\text { LAKE ID }\end{array}$ & 0.057 & 4.43 & $<0.001$ \\
\hline \multicolumn{5}{|l|}{ Phytoplankon } \\
\hline NUT & $\begin{array}{l}\text { DISP } \\
\text { LAKE ID }\end{array}$ & 0.091 & 10.29 & $<0.001$ \\
\hline DISP & $\begin{array}{l}\text { NUT } \\
\text { LAKE ID }\end{array}$ & 0.061 & 3.41 & 0.002 \\
\hline NUT × DISP & $\begin{array}{l}\text { NUT } \\
\text { DISP } \\
\text { LAKE ID }\end{array}$ & 0.052 & 3.066 & 0.002 \\
\hline \multicolumn{5}{|l|}{ Bacterioplankton } \\
\hline NUT & $\begin{array}{l}\text { DISP } \\
\text { LAKE ID }\end{array}$ & 0.11 & 11.72 & $<0.001$ \\
\hline DISP & $\begin{array}{l}\text { NUT } \\
\text { LAKE ID }\end{array}$ & 0.05 & 2.73 & $<0.001$ \\
\hline NUT $\times$ DISP & $\begin{array}{l}\text { NUT } \\
\text { DISP } \\
\text { LAKE ID }\end{array}$ & 0.046 & 2.65 & $<0.001$ \\
\hline
\end{tabular}

HDISP (see Appendix S3). Zooplankton species richness was negatively affected by nutrient addition and positively by dispersal (see Appendix S4). 

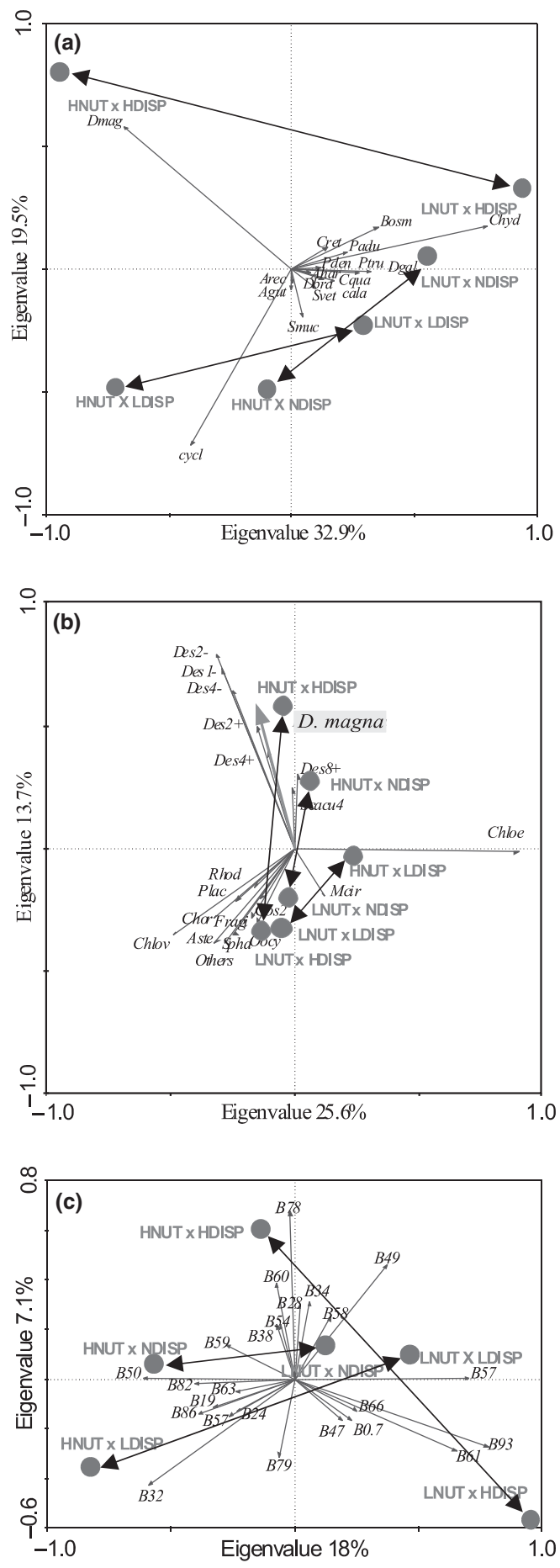

Figure 2 Biplot of principal component analysis representing the response of zooplankton (a), phytoplankton (b), and bacterioplankton (c) community composition to the experimental treatments. Centroids (filled circles) indicate the average location of communities belonging to the same multifactorial treatment combinations of nutrient addition and dispersal. For phytoplankton and bacterioplankton only species are shown for which a minimum of $5 \%$ of the variation can be explained by the treatments. In (b), Daphnia magna is plotted as a supplementary variable; abbreviations of species are given in Table S3. In (c), each OTU is labelled by a code in which the number is referring to a specific band location on the DGGE-gel. Data were Hellinger transformed prior to analysis. HNUT, high nutrient content; LNUT, low nutrient content; NDISP, no dispersal; LDISP, low dispersal; and HDISP, high dispersal; DGGE, denaturing gradient gel electrophoresis.
Table 3 Redundancy analysis results, testing for the effect of nutrient addition (NUT) within each of the dispersal treatments for zoo-, phyto- and bacterioplankton communities in the experimental containers. In all these analyses, we specified LAKE ID as covariable to adjust for differences among lake origin of inoculation samples

\begin{tabular}{llcr}
\hline & $\mathrm{R}^{2}$ & $F$ & $P$-value \\
\hline Zooplankton & & & \\
$\quad$ No dispersal & 0.085 & 3.64 & 0.008 \\
Low dispersal & 0.20 & 8.90 & $<0.001$ \\
$\quad$ High dispersal & 0.59 & 44.008 & $<0.001$ \\
$\begin{array}{l}\text { Phytoplankton } \\
\text { No dispersal }\end{array}$ & 0.13 & 4.82 & $<0.001$ \\
Low dispersal & 0.11 & 3.55 & 0.017 \\
High dispersal & 0.22 & 8.033 & $<0.001$ \\
Bacterioplankton & & & $<0.001$ \\
No dispersal & 0.086 & 2.86 & $<0.001$ \\
Low dispersal & 0.19 & 7.73 & $<0.001$ \\
High dispersal & 0.22 & 7.83 & \\
\hline
\end{tabular}

\section{Phytoplankton}

High nutrient addition resulted in a strong increase of chlorophyll a concentrations throughout the course of the experiment (Fig. 1B; Table 1). According to RDA analysis, the nutrient addition and dispersal treatments affected phytoplankton community composition and there was also an interaction between both factors (Fig. 2B; Table 2). Overall, nutrient addition resulted in a strong increase in the contribution of Desmodesmus species, whereas containers with low nutrient addition tended to be mainly characterised by a variety of other phytoplankton taxa (Fig. 2B). Analyses for each of the dispersal treatments separately showed an increase of the impact of nutrient addition with increasing dispersal intensity (13, 11 and $22 \%$ of the total community variation explained by nutrient addition in the no, low and high dispersal treatment respectively) (Table 3). When dispersal was tested separately for each of the nutrient addition levels, there was only a significant effect in containers with high nutrient addition (see Table S1). In containers with high nutrient addition, colony size of the Desmodesmus morphs decreased with dispersal (Fig. 1C): large colonial morphs were most abundant in the absence of dispersal, whereas unicellular morphs were mainly associated with high levels of dispersal. This was also confirmed by an ANOVA on the weighted average of colony cell number $(\mathrm{F}(2$, $30)=64.28, P<0.001)$. Phytoplankton richness was positively affected by dispersal, but only at low nutrient addition levels (see Appendix S4).

\section{Bacterioplankton}

Nutrient addition and dispersal treatments affected the DGGE profiles of the bacterioplankton communities (Table 2; Fig. 2C). The compositional response to the nutrient addition increased with increasing dispersal (nutrient $\times$ dispersal interaction): the contribution of the nutrient addition to the community variation increased from 9 , over $19-22 \%$ in the no, low and high dispersal treatment respectively (Table 3). Dispersal was equally important under low and high nutrient addition (see Table S1). The number of OTUs was significantly higher under high than low nutrient addition levels, but only in the HDISP treatment (see Appendix S4). 


\section{Indirect dispersal-mediated intertrophic interactions}

Zooplankton grazing rates on the phytoplankton community, as measured by the in situ grazing experiments, increased with dispersal intensity, but only at high nutrient levels (Fig. 1d, Table 1). Overall, grazing pressure was positively correlated with $D$. magna density (Spearman rank correlation: $\left.n=96, \mathrm{r}_{\mathrm{s}}=0.477, P<0.001\right)$. This correlation was especially strong in the mesocosms with high nutrient levels $\left(n=48, \mathrm{r}_{\mathrm{s}}=0.704, P<0.001\right)$, but insignificant in containers with low levels of nutrients $\left(n=48, \mathrm{r}_{\mathrm{s}}=0.0688, P=0.642\right)$.

Phytoplankton community composition was significantly associated with the population density of $D$. magna and dispersal intensity, but only under high nutrient conditions (Fig. 3; Table S2). Under these conditions, the dispersal treatment and $D$. magna jointly explained $c$. $35 \%$ of the total phytoplankton community variation. A large fraction of the variation explained by $D$. magna proved highly collinear with dispersal $(15 \%)$, whereas the conditional effect of $D$. magna was relatively small (4\%). At high nutrient concentrations, weighted average Desmodesmus colony size was negatively correlated to $D$. magna density $\left(n=48, \mathrm{r}_{\mathrm{s}}=-0.546, P<0.001\right.$; Figure S1). We detected very similar patterns when using the estimated zooplankton grazing rate and zooplankton dry biomass as explanatory variables in these analyses (results not shown).

The dispersal gradient, D. magna density and phytoplankton community composition jointly explained $17 \%$ of the compositional variation in the bacterioplankton communities under high nutrient conditions (Fig. 3; Table S2). The marginal effects of each of the three categories of variables were highly significant (explaining 12, 7 and $14 \%$ of bacterial community variation respectively). Variation partitioning showed that relatively large fractions of community variation were explained by joint effects, mainly of all three variable categories together $(5 \%)$ or effects shared by the dispersal treatment and phytoplankton community composition $(6 \%)$. In contrast, the conditional effects of the explanatory variables were relatively low and statistically insignificant. The effect of $D$. magna was almost entirely collinear with dispersal and phytoplankton community composition. Under low nutrient conditions, dispersal contributed most to bacterioplankton community variation $(11 \%)$.

\section{DISCUSSION}

We observed highly significant interaction effects between the dispersal and nutrient addition treatments for the zoo-, phyto- and

\section{Phytoplankton community}

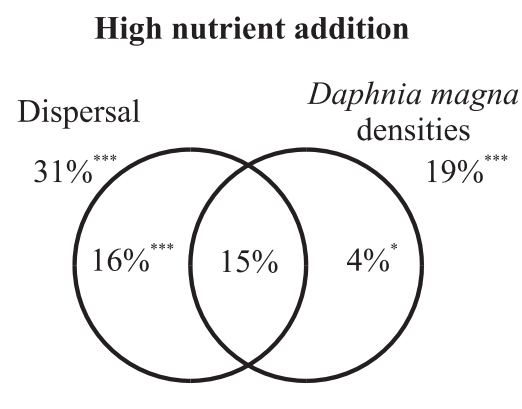

Low nutrient addition

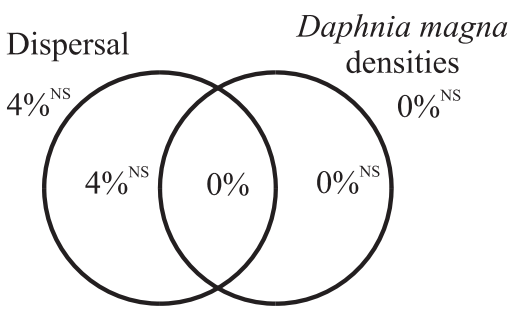

\section{Bacterioplankton community}

\section{High nutrient addition}

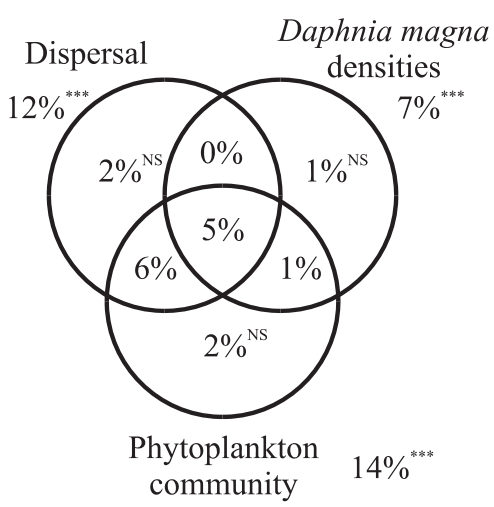

Low nutrient addition

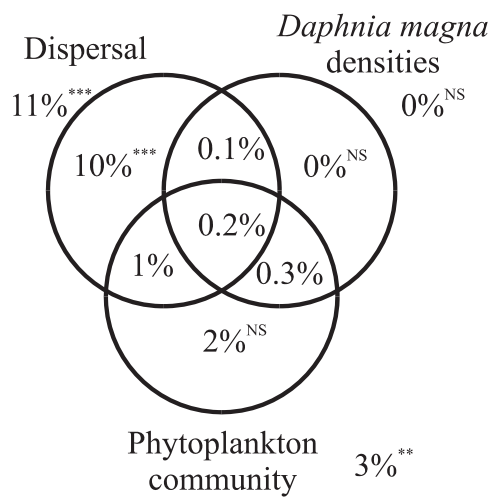

Figure 3 Venn diagrams presenting the results of variation partitioning analyses performed on the phytoplankton and bacterial community data at low and high nutrient levels, separately. For the phytoplankton communities, the diagrams represent the unique and shared contributions of the dispersal treatment and Daphnia magna population densities. For the bacterial communities, the diagrams represent the unique and shared contributions of the dispersal treatment, Daphnia magna densities and phytoplankton community composition. Figures outside the diagrams represent the $\mathrm{R}^{2}$ of the marginal effects of the factors tested. Figures within the diagrams represent the $\mathrm{R}^{2}$ of the conditional effects. $\mathrm{R}^{2}$-values express the percentage of total variance explained. Asterisks denote significance level: $* P<0.05$; $* * P<0.01$; $* * * P<0.001$; NS, not significant. 
bacterioplankton communities. In each of these functional groups, the interaction effects reflected increased strength in community compositional shifts to nutrient addition with increasing rates of dispersal. These results show that the degree of connectivity among habitat patches within a metacommunity can profoundly affect the composition of the constituent communities by facilitating species sorting. In addition, the results of the variation partitioning analyses indicate that responses observed for specific communities (in casu phytoplankton and bacterioplankton) are not uniquely caused by the physical exchange of members of those communities, but also indirectly by changed trophic interactions that result from the impact of dispersal at other trophic levels (in casu zooplankton).

For zooplankton, we observed enhanced compositional responses to the productivity gradient already at low exchange rates. A shift from no to low dispersal (i.e. from no to the weekly exchange of $0.02 \%$ of container volumes) more than doubled the community response strength to the nutrient addition treatment (see Table 3). This response was still considerably enhanced upon further increase in connectivity, as the nutrient addition treatment contributed to a total of $59 \%$ of the variation in zooplankton community composition at maximal dispersal rates. These dispersal-mediated responses also affected ecosystem functioning: zooplankton grazing rates measured in situ were higher at high than low nutrient conditions, but only at the highest levels of dispersal. This effect mainly seemed to result from the response of one single zooplankton key-stone species, i.e. Daphnia magna. Although most zooplankton species responded negatively to nutrient addition, D. magna performed very well under high nutrient conditions. D. magna was detected in only a limited number of experimental communities in the absence of dispersal. With increasing dispersal rates, the species expanded within the metacommunity and became dominant in containers with high nutrient levels. The species was so influential that the response of its populations to the experimental treatments constituted most of the response patterns of total zooplankton community biomass. Consequently, zooplankton grazing rates also correlated strongly with D. magna population density. In conclusion, our results demonstrate the potential importance of dispersal-related spatial dynamics for ecosystem functioning, in agreement with predictions of theoretical metacommunity models (Loreau et al. 2003; Gonzalez \& Loreau 2009).

We observed effects of the dispersal treatment on the compositional response of the phyto- and bacterioplankton communities to nutrient enrichment. Although such effects can be considered evidence for dispersal limitation, our results suggest that they may also have resulted from indirect effects, such as dispersal-mediated changes in trophic interactions. Indeed, as discussed above, increased dispersal rates resulted in a strong increase of zooplankton grazing pressure at high nutrient levels. Variables related to this gradient (i.e. D. magna population density, zooplankton biomass, grazing rates) explained a substantial part of the variation in phytoplankton community composition at high nutrient levels and most (79\%) of this explained variation was collinear with the dispersal treatment. The quality of the shifts in phytoplankton characteristics also strongly suggests grazing intensity as a strong community structuring factor. Along with a gradient of increasing dispersal intensity and increasing population densities of $D$. magna, average Desmodesmus colony cell number decreased and large colonial and spined Desmodesmus morphs were replaced by spineless, unicellular or smaller colonial morphs. Given that spine and colony formation are well-known defences against zooplankton grazing, this response appears contra-intuitive. However, it can be well understood in the light of a trade-off between grazing resistance and grazing tolerance (Agrawal 1998; Chase et al. 2000). Although colony formation may indeed decrease the vulnerability of phytoplankton cells to grazing by small and intermediate sized zooplankton, such defence is largely ineffective against grazing by zooplankton with a very wide food particle size range such as D. magna (Matveev et al. 2000; Mayeli et al. 2004; Sarnelle 2005). The phytoplankton community composition shift observed by us in response to the dispersal and grazing gradients thus represents a shift towards smaller colonies and single cells that may be more vulnerable to predation, but that are better able to compensate for mortality losses through faster population growth (Agrawal 1998). Our results thus suggest that the dispersal treatment affected the phytoplankton community in an indirect way through an intensification of top-down control by zooplankton. D. magna thrived under high nutrient addition, and release from dispersal limitation allowed this species to successfully spread through the metacommunity, developing dense populations in containers with high nutrients, which then resulted in major quantitative and qualitative changes in the phytoplankton communities compared with mesocosms where no dispersal was applied. It should be noted, however, that our statistical analysis suggests that such indirect dispersal induced trophic interactions can only account for about half of the phytoplankton community variation that was caused by the dispersal treatment, which indicates that phytoplankton communities were also directly affected by the dispersal treatment.

Similar to our observations for the phytoplankton communities, effects of the dispersal treatment on bacterial communities were not only due to increased exchange rates of bacteria among mesocosms, but may also have been shaped by several indirect mechanisms. According to our variation partitioning results, a large part $(65 \%)$ of the total explained bacterioplankton variation was explained by variation among phytoplankton communities that was also collinear with the dispersal treatment. Phytoplankton community composition can affect bacterioplankton composition through competition for nutrients (Cherif \& Loreau 2007; Daufresne et al. 2008) or via the composition of DOC that it excretes (Giroldo et al. 2007). Dispersal may thus have affected the composition of bacteria indirectly by its direct and indirect effects on the composition of phytoplankton communities. An important subfraction of the variation in bacterial community composition was also collinear with $D$. magna. Zooplankton can affect bacterioplankton directly through selective grazing (Zollner et al. 2003; Hambright et al. 2007) or indirectly by structuring bacterivore communities (e.g. ciliates, flagellates; Jürgens 1994; Jürgens \& Stolpe 1995; Lampert 2006). The strong collinearity in a large fraction of the variation in zooplankton composition, phytoplankton composition and dispersal suggests that the dispersal treatment affected an important part of the bacterioplankton variation via a cascade of effects: increased dispersal rates affected zooplankton community composition and grazing rates, which induced changes in the phytoplankton community composition, which then affected bacterioplankton community composition.

Although our analysis suggests that there is a direct effect of dispersal limitation on phytoplankton species composition in our experiment, we have no unequivocal evidence for dispersal limitation of bacteria under high nutrient conditions, because the effects of the dispersal treatment was strongly reduced and became insignificant when $D$. magna and phytoplankton community composition were accounted for. There were, however, indications for dispersal limitation of bacteria at low nutrient levels. Dispersal limitation is 
generally assumed to be of minor importance in determining the composition of micro-organisms, because taxa are supposed to be omnipresent, especially at small spatial scales (Finlay \& Clarke 1999; Finlay 2002). Our data, nevertheless, also suggest that dispersal limitation in micro-organisms can matter at the spatial and temporal scales of our experiment. Indeed, we found indications for enhanced species sorting with increasing dispersal rates by physical exchange of medium and organisms for phytoplankton and bacteria after correction for indirect effects caused by dispersal limitation of zooplankton. This suggests that not all taxa were present in the original inocula or at least not in sufficient densities to have an impact during the course of our experiment. The fact that our results indicate more direct dispersal limitation effects in the low than in the high nutrient treatment may reflect that existent communities can intrinsically more easily adapt to high than to low nutrient conditions, or alternatively may reflect that nutrient rich habitats are more abundant in the study region so that these tend to be more omnipresent than species that are pre-adapted to low nutrient conditions.

The results of our study have important implications for the interpretation of metacommunity patterns observed in the field. An increasing number of studies (Cottenie 2005; Beisner et al. 2006; Van der Gucht et al. 2007; Pandit et al. 2009; Declerck et al. 2011) have tried to link patterns of community variation with existing metacommunity paradigms, by partitioning community variation into spatial and environmental components, using direct gradient ordination techniques. Our results show that spatial structures observed in such studies on natural metacommunities may not only be caused by dispersal limitation or mass effects, but may also emerge as the result of strong ecological interactions with other groups of organisms, which are themselves impacted by dispersal limitation or mass effects. A spatial signal can emerge from an insufficient sampling of relevant variation in environmental conditions (Langenheder \& Ragnarsson 2007). If variation in the environment is not measured and spatially structured, it will result in a spatial signal. Our results indicate that species composition at other trophic levels is an important environmental factor to be taken into account when determining the response of a given group of organisms to environmental and spatial factors. Failing to incorporate this information may introduce a significant spatial signal, even when the focal group of organisms is not dispersal limited and mainly the subject of species sorting.

\section{CONCLUSIONS}

Our study provides evidence that increased dispersal rates within a metacommunity can strongly mediate the compositional response of zoo-, phyto- and bacterioplankton communities to a gradient in primary productivity, and that this strong response can be largely generated by the response of a limited number of keystone species at higher trophic levels (such as Daphnia magna in our experiment) that are dispersal limited and strongly affect the intensity of trophic interactions. We show that key-stone species mediated impacts cause major changes in ecosystem functioning (grazing pressure) and lead to apparent dispersal effects at lower trophic levels (phytoplankton and bacterioplankton). Our results suggest that these indirect effects of metacommunity structure may strongly impact species composition in local communities and even ecosystem functioning, and should be taken into consideration in metacommunity analyses.

\section{ACKNOWLEDGEMENTS}

The authors thank Glenn Van heugten for practical assistance with the zooplankton sample enumeration and Sofie D'Hondt and Tine Verstraete for the practical assistance with the DGGE analysis. Dino Verreydt was funded by the Institute for the Promotion of Innovation through Science and Technology in Flanders (IWT-Vlaanderen). MJ Villena was funded by the Ministry of Education and Science from Spain (Postdoctoral 2007-0216). Pieter Vanormelingen is postdoctoral Research Fellow with the Flemish Fund for Scientific Research. This research was financially supported by FWO project G.0506.07 and by K.U.Leuven Research Fund projects GOA/2008/06 and $\mathrm{PF} / 2010 / 07$.

\section{AUTHORSHIP}

The experiment was designed by SD, LDM, DV, ED and WV. The mesocosm experiment was carried out by DV, ED and MJV, sample analysis was performed by DV, MJV and KVDG. Troubleshooting and discussing data analysis was mainly done by SD, DV, LDM and WV. Data analysis was mainly done by DV and SD, with contributions of PV and KVDG. The manuscript was written by DV, SD and LDM, with editing by PV, ED and KVDG.

\section{REFERENCES}

Agrawal, A.A. (1998). Algal defense, grazers, and their interactions in aquatic trophic cascades. Acta. Oecol., 19, 331-337.

Beisner, B.E., Peres-Neto, P.R., Lindström, E.S., Barnett, A. \& Longhi, M.L. (2006). The role of environmental and spatial processes in structuring lake communities from bacteria to fish. Ecology, 87, 2985-2991.

Bohonak, A.J. \& Jenkins, D.G. (2003). Ecological and evolutionary significance of dispersal by freshwater invertebrates. Ecol. Lett., 6, 783-796.

Chase, J.M., Leibold, M.A. \& Simms, E. (2000). Plant tolerance and resistance in food webs: community-level predictions and evolutionary implications. Evol. Ecol., 14, 289-314.

Cherif, M. \& Loreau, M. (2007). Stoichiometric constraints on resource use, competitive interactions, and elemental cycling in microbial decomposers. Am. Nat., 169, 709-724.

Cottenie, K. (2005). Integrating environmental and spatial processes in ecological community dynamics. Ecol. Lett., 8, 1175-1182.

Cottenie, K. \& De Meester, L. (2004). Metacommunity structure: synergy of biotic interactions as selective agents and dispersal as fuel. Ecology, 85, 114-119.

Daufresne, T., Lacroix, G., Benhaim, D. \& Loreau, M. (2008). Coexistence of algae and bacteria: a test of the carbon hypothesis. Aquat. Microb. Ecol., 53, 323-332.

Declerck, S.A.J., Coronel, J.S., Legendre, P. \& Brendonck, L. (2011). Scale dependency of processes structuring metacommunities of cladocerans in temporary pools of High-Andes wetlands. Ecography, 34, 296-305.

Duffy, J.E. (2009). Why biodiversity is important to the functioning of real-world ecosystems. Front. Ecol. Environ., 7, 437-444.

Finlay, B.J. (2002). Global dispersal of free-living microbial eukaryote species. Science, 296, 1061-1063.

Finlay, B.J. \& Clarke, K.J. (1999). Ubiquitous dispersal of microbial species. Nature, 400, 828-828.

Flössner, D. (2000). Die Haplopoda und Cladocera (obne Bosminidae) Mitteleuropas. Backhuys, Leiden.

Giroldo, D., Ortolano, P.I.C. \& Vieira, A.A.H. (2007). Bacteria-algae association in batch cultures of phytoplankton from a tropical reservoir: the significance of algal carbohydrates. Freshw. Biol., 52, 1281-1289.

Gonzalez, A. \& Loreau, M. (2009). The causes and consequences of compensatory dynamics in ecological communities. Annu. Rev. Ecol. Evol. Syst., 40, 393 414. 
Hambright, K.D., Hairston, N.G., Schaffner, W.R. \& Howarth, R.W. (2007). Grazer control of nitrogen fixation: synergisms in the feeding ecology of two freshwater crustaceans. Fundam. Appl. Limnol., 170, 89-101.

Hillebrand, H. \& Matthiessen, B. (2009). Biodiversity in a complex world: consolidation and progress in functional biodiversity research. Ecol. Lett., 12, 14051419.

Howeth, J.G. \& Leibold, M.A. (2008). Planktonic dispersal dampens temporal trophic cascades in pond metacommunities. Ecol. Lett., 11, 245-257.

Howeth, J.G. \& Leibold, M.A. (2010). Species dispersal rates alter diversity and ecosystem stability in pond metacommunities. Ecology, 91, 2727-2741.

Jenkins, D.G., Brescacin, C.R., Duxbury, C.V., Elliott, J.A., Evans, J.A., Grablow, K.R. et al. (2007). Does size matter for dispersal distance? Glob. Ecol. Biogeogr., 16, 415-425.

Jürgens, K. (1994). Impact of Daphnia on planktonic microbial food webs - a review. Aquat. Microb. Ecol., 8, 295-324.

Jürgens, K. \& Stolpe, G. (1995). Seasonal dynamics of crustacean zooplankton, heterotrophic nanoflagellates and bacteria in a shallow, eutrophic lake. Freshw. Biol., 33, 27-38.

Lampert, W. (2006). Daphnia: model herbivore, predator and prey. Pol. J. Ecol., 54, 607-620.

Langenheder, S. \& Ragnarsson, H. (2007). The role of environmental and spatial factors for the composition of aquatic bacterial communities. Ecology, 88, 2154 2161.

Legendre, P. \& Gallagher, E.D. (2001). Ecologically meaningful transformations for ordination of species data. Oecologia, 129, 271-280.

Leibold, M.A. \& Norberg, J. (2004). Biodiversity in metacommunities: Plankton as complex adaptive systems? Limnol. Oceanogr., 49, 1278-1289.

Lepš, J. \& Šmilauer, P. (2003). Multivariate Analysis of Ecological Data Using CANOCO. Cambridge University Press, New York.

Loreau, M. \& Mouquet, N. (1999). Immigration and the maintenance of local species diversity. Am. Nat., 154, 427-440.

Loreau, M., Mouquet, N. \& Gonzalez, A. (2003). Biodiversity as spatial insurance in heterogeneous landscapes. Proc. Natl Acad. Sci. USA, 100, 12765-12770.

Matthiessen, B. \& Hillebrand, H. (2006). Dispersal frequency affects local biomass production by controlling local diversity. Ecol. Lett., 9, 652-662.

Matveev, V., Matveeva, L. \& Jones, G.J. (2000). Relative impacts of Daphnia grazing and direct stimulation by fish on phytoplankton abundance in mesocosm communities. Freshw. Biol., 44, 375-385.

Mayeli, S.M., Nandini, S. \& Sarma, S.S.S. (2004). The efficacy of Scenedesmus morphology as a defense mechanism against grazing by selected species of rotifers and cladocerans. Aquat. Ecol., 38, 515-524.

McCauley, S.J. (2006). The effects of dispersal and recruitment limitation on community structure of odonates in artificial ponds. Ecography, 29, 585-595.

Michels, E., Cottenie, K., Neys, L. \& De Meester, L. (2001). Zooplankton on the move: first results on the quantification of dispersal of zooplankton in a set of interconnected ponds. Hydrobiologia, 442, 117-126.

Mouquet, N. \& Loreau, M. (2003). Community patterns in source-sink metacommunities. Am. Nat., 162, 544-557.

Naeslund, B. \& Norberg, J. (2006). Ecosystem consequences of the regional species pool. Oikos, 115, 504-512.

Oksanen, J., Blanchet, F.G., Kindt, R., Legendre, P., O’Hara, R.G., Simpson, G.L. et al. (2010). vegan: Community Ecology Package. R package version 1.17-2. Available at: http://CRAN.R-project.org/package= vegan.

Ozinga, W.A., Schamine, J.H.J., Bekker, R.M., Bonn, S., Poschlod, P., Tackenberg, O. et al. (2005). Predictability of plant species composition from environmental conditions is constrained by dispersal limitation. Oikos, 108, 555-561.
Pandit, S.N., Kolasa, J. \& Cottenie, K. (2009). Contrasts between habitat generalists and specialists: an empirical extension to the basic metacommunity framework. Ecology, 90, 2253-2262.

Pärtel, M. \& Zobel, M. (2007). Dispersal limitation may result in the unimodal productivity-diversity relationship: a new explanation for a general pattern. $J$. Ecol., 95, 90-94.

Peres-Neto, P.R., Legendre, P., Dray, S. \& Borcard, D. (2006). Variation partitioning of species data matrices: estimation and comparison of fractions. Ecology, 87, 2614-2625.

R Development Core Team (2011). R: A Language and Environment for Statistical Computing. R Foundation for Statistical Computing, Vienna. Available at: http:// www.R-project.org.

Sarnelle, O. (2005). Daphnia as keystone predators: effects on phytoplankton diversity and grazing resistance. J. Plankton Res., 27, 1229-1238.

Scheffer, M. (1998). Ecology of Shallow Lakes, 1st edn. Kluwer Academic Publishers, Dordrecht; Boston.

Sherr, E.B. \& Sherr, B.F. (1993). Preservation and storage of samples for enumeration of heterotrophic protists. In: Handbook of Methods in Aquatic Microbial Ecology (eds Kemp, P.F., Sherr, B.F., Sherr, E.B. \& Cole, J.J.). Lewis Publishers, Boca Raton, pp. 207-212.

Shurin, J.B., Cottenie, K. \& Hillebrand, H. (2009). Spatial autocorrelation and dispersal limitation in freshwater organisms. Oecologia, 159, 151-159.

Staddon, P., Lindo, Z., Crittenden, P.D., Gilbert, F. \& Gonzalez, A. (2010). Connectivity, non-random extinction and ecosystem function in experimental metacommunities. Ecol. Lett., 13, 543-552.

Van der Gucht, K., Cottenie, K., Muylaert, K., Vloemans, N., Cousin, S., Declerck, S. et al. (2007). The power of species sorting: Local factors drive bacterial community composition over a wide range of spatial scales. Proc. Natl Acad. Sci. USA, 104, 20404-20409.

Vanormelingen, P., Vyverman, W., De Bock, D., Van der Gucht, K. \& De Meester, L. (2009). Local genetic adaptation to grazing pressure of the green alga Desmodesmus armatus in a strongly connected pond system. Limnol. Oceanogr., 54, 503511.

Zollner, E., Santer, B., Boersma, M., Hoppe, H.G. \& Jurgens, K. (2003). Cascading predation effects of Daphnia and copepods on microbial food web components. Freshw. Biol., 48, 2174-2193.

\section{SUPPORTING INFORMATION}

Additional Supporting Information may be downloaded via the online version of this article at Wiley Online Library (www.ecologyletters.com).

As a service to our authors and readers, this journal provides supporting information supplied by the authors. Such materials are peer-reviewed and may be re-organised for online delivery, but are not copy edited or typeset. Technical support issues arising from supporting information (other than missing files) should be addressed to the authors.

Editor, James Grover

Manuscript received 10 August 2011

First decision made 12 September 2011

Manuscript accepted 5 December 2011 